\title{
COMPENSATION FOR OCCUPATIONAL DISEASES
}

\author{
GeORge E. BeERS
}

The system of compensation for occupational diseases is a corollary to that of workmen's compensation for accident, for the basis of the two is a common one. For a liability based on fault there is substituted by the compensation system a burden on industry which eventually shifts itself upon the consumer.

The underlying theory is simple. It treats the wastage of man-power as it does the wearing out of machinery-as an inevitable incident of industry, to be borne in the first instance by industry. It recognizes that it is humanly impossible to entirely avoid accident, and that the required standard of care of a reasonably careful man is really a counsel of perfection, calling for a degree of virtue to which none can fully attain. Generally speaking, the compensation acts know no distinction between careless and careful. 2 If it were possible to encourage care and discourage negligence by such a differentiation, the attempt to do so would lead into many of the very dificulties which the compensation system seeks to avoid, for one of the great incidental advantages is that it does away with much of the uncertainty and expense of litigation.

Compensation acts of the involuntary type, as well as those styled voluntary, are now upheld with practical unanimity of judicial opinion. The volition, however, on the part of the employer in even the voluntary act is of a very limited character, consisting as it does of a right of choice between a new system and an old system shorn of important protections and benefits to the employer.

The pressure to adopt the new system generally assumes the form of a statutory provision taking away from the non-consenting employer his so-called common law defenses of contributory negligence, negligence of fellow servant and assumption of risk.

The compensation system has now proven itself, and its beneficial effect upon those directly concerned and upon society as

1 "The plain purpose of the compensation law is to make the risl: of the accident one of the industry itself, to follow from the fact of the injury, and hence that compensation on account thereof should be treated as an element in the cost of production, added to the cost of the article and borne by the community in general." 1 SchNEmER, Wonkanex's CoirPEASATION LATW (1922) § 1, p. 2.

${ }^{2}$ Injuries through serious and wilful misconduct are, however, excepted practically everywhere. 
a whole is no longer a matter of theory. Employers and employes with hardly a dissenting note now unite in its praise. This attitude is, however, the result of a gradual change of opinion on the part of several influential elements of society. Employers looked with apprehension upon a system which in effect furnished a form of insurance, and the idea that there could be liability except when based upon fault was a new one to the bar, traditionally a conservative element. But, somehow, that which was feared by the employers did not seem to happen, and the bar gradually adjusted itself to a new series of legal concepts. The same conservatism has manifested itself in the case of every enlargement of the scope of the compensation principle. It has been said that there was no stopping place between compensation for occupational diseases and complete health insurance. That one tends to run unto the other can not be denied, and yet experience has shown that there is a real line of demarcation.

Were it not for two considerations a theoretically sound system of compensation would give a full wage for the whole period of total incapacity, a full equivalent for the time lost through partial incapacity, medical attendance as long as needed and an amount in case of death which, figured on actuarial principles, would place the family in the same position financially as though the death had not occurred. Here, as throughout the whole law, the objective is a complete equivalent. In compensation, as in the determination of ordinary legal rights, the full attainment of this ideal is impossible. In fixing compensation, concessions must be made both to the shortcomings of human nature and to practical exigencies which exist because of the fact that social legislation of this character is slow in getting a foothold, representing as it does a new series of conceptions and placing a burden which may not readily distribute itself among those who should bear it in the end.

We have, therefore, a system of compensation which grants to the injured workman a percentage of his loss, leaving a part to fall upon him as a spur and incentive to effort, a rough attempt to determine one's loss through the deprivation of a member or an interference with a function, the giving of medical services for a period often shortened arbitrarily and an allowance in case of death which is generally limited to a time much less than the workman would probably have lived had it not been for. the accident or disease.

Sporadic efforts have been made to get at more exact results. In California, ${ }^{3}$ for instance, the attempt is made to dif-

\footnotetext{
${ }^{3}$ The general spirit of the system illustrated by the California legislation appears in the discussions of the report of the Committee on Statistics
} 
ferentiate between the effect of a certain injury upon one of a certain employment and its effect upon one of a different employment, for it is obvious that a finger may have a greater money value to a violinist than to one who works with his brain only or does rough work with his hands. The relation which the dependents bear to the deceased workman is an element often taken into account." These variations from the more common fixed type are obviously in the right direction, but are subject to important limitations. It is more important that the law should be clear, simple, easily understood and practically workable than that it should be theoretically perfect.

There is no sound difference in principle between an incapacity or a death caused by a disease which has its roots in occupation and one resulting from accident in the usual sense of the term. As said in the best known American work on the subject of workmen's compensation :

"The distinction which is drawn in nearly all the acts between 'accidental' injuries and 'occupational diseases' is extremely unjust and illogical. The principal argument in favor of the workmen's compensation acts, hear'd on all hands, is that each industry should care for the human wrecks which it creates. The man who breathes lead fumes and contracts plumbism, or inhales marble or other dust from the air in the shop where he is working and is totally incapacitated from pneumoconiosis, is to a very much greater extent, the victim of the industry in which he is engaged, than is the workman who falls downstairs in going from one floor to another in the shop and breaks both legs. The dependents of a workman who for months or possibly years lingers in a helpless condition from an occupational disease, and then dies, are infinitely worse off, as a rule, than are the widows and children of workmen who are taken away suddenly by an 'accidental' injury."

In the discussions of the International Association of Commissioners, made up of the commissioners and others concerned in the administration of compensation acts or especially interested in the subject, an association which has done much to perfect the law on the subject and to standardize administration, much used to be heard of the dramatic incident attendant upon accident. That dramatic incident is, however, in many accidents utterly lacking. The strain, for instance, may have been unrecognized, and in many a doubtful case its very existence is determined only by reasoning back from subsequent

and Compensation Insurance of the International Association of Commissions, printed in BULLETIN OF THE UNITED STATES BUREAU OF LABOR Statistics No. 333 (1923) 72 et seq., under the head of "Standard Permanent Disability Schedule."

4 As in New York.

5 BradBuRY, WORKMIEN's Codipensation (\$d ed. 1917) 7. 
conditions. When the subject is pursued we reach a point where it is hard to differentiate between an accident in the ordinary sense and an exposure which causes disease.

There are, however, certain differences between accident and disease which must be reckoned with in the attempt to extend the system of compensation to occupational disease. Speaking generally, an accident arrests the attention and makes an obvious appeal; the disease usually creeps on slowly, and may be recognized only when it has fully developed. There may be two similar employments, one apparently innocuous, the other attended with conditions which seem to be freighted with danger. The former in point of fact may be slowly killing the workman, while the latter may be simply making him uncomfortable. Perhaps no better illustration of this can be given than in dusty employments. The man who works among apparently clean surroundings upon one kind of stone may be fast developing a pneumoconiosis, while one who is shoveling coal or ashes may become covered with dirt but really suffer no harm. ${ }^{\circ}$

Other points of difference will appear as we proceed. The problem of the two kinds of compensation being really one, there is obviously a distinct advance in the recognition of the duty owed to the employee when the law passes from a condition which takes account of accident only to a state where compensation is made also for occupational disease. ${ }^{7}$

All systems of compensation, whether for accident or occupational disease, are the creatures of statute. These statutes have grown out of the recognition of social needs. They are shaped in a peculiar sense by the industrial conditions in the jurisdictions in which they are passed. While there has been legislative borrowing, the statutes borrowed from other jurisdictions have been so changed to meet local requirements that there is a wide variation. The plan of compensation of each jurisdiction is hence definitely a system in itself. Any general principle is apt to be inapplicable at any one point.

The individual character of the legislation on workmen's compensation for accident and- occupational disease is in no way better illustrated than in the experience with those subjects of the National Conference on Uniform State Laws. ${ }^{8}$ This com-

6 There exists a considerable body of literature, largely in the form of pamphlets and reports, upon the relative effects of exposures to dust from quartz and marble and other stone and metallic substances. Generally speaking, in the administration of the acts the facts have to be developed as in a court proceeding by expert evidence.

'It has been said that "no law in its original enactment made specific provision for compensating occupational diseases." BULLETIN OF THE United States Bureau of Labor Statistics No. 379 (1925) (by Lindley D. Clark).

89 U. L. A. (1923) 233, 299. 
mission, after years of study, and after hearing the expression of views from all parts of the country, prepared drafts which were recommended for adoption. These drafts met with no criticism, but nevertheless failed of passage practically everywhere. The obvious reason for this was that legislation of a general character did not seem to fit the varying needs and desires of different jurisdictions.

Fortunately, we have in convenient form, and brought practically down to the minute, indexes to such legislation by means of which the terms of the statutory law throughout the jurisdictions can be ascertained. ${ }^{\circ}$ This is, however, no easy task, as in a new and living subject amendments have followed fast on the heels of legislation. For our present purpose, we need to deal with this statutory material only in the most general way for purposes of illustration and comparison.

\section{The Ways in Which Occupational Diseases Becorme COMPENSABLE; Three LINES OF ThOUghT}

There are three different ways in which in different jurisdictions occupational diseases become compensable;

First-They are sometimes included by implication under the general terms of the workmen's compensation act.

Second-They are made compensable generally by apt language providing that compensation is to be made for all occupational diseases, with perhaps specific exceptions.

Third-A schedule of diseases is given, and a right of compensation is created for diseases named in such schedule.

Occupational Diseases Under the General Clanses of the Worlmen's Compensation Act. Generally, occupational diseases do not fall within the general terms of the compensation acts as they are construed by the courts. The idea of compensation for accident took root much earlier than did that of compensation for disease. There is frequently in legislation no direct reference to disease, and in the discussions which have preceded the original legislation of the several states there has seldom been any consideration of the subject of occupational disease.

a One is the Digest (10th ed.) prepared by Professor F. Robertson Jones under the auspices of the Workmen's Compensation Publicity Bureau, and the other the Digest prepared under the direction of the National Bureau of Casualty and Surety Undervriters. In addition to these, Bulletin $\mathbf{4 2 3}$ of the United States Bureau of Labor Statistics, entitled Wonkuss's COMPENSATION LEgISLATION OF THE UNITEd STATES AND CANADA AS OF JULX 1, 1926, reprints the statutory provisions up to that date. The various points made throughout this article will find ready illustration in the tabulations of these two Digests and in the specific language of the statutes set out in the reprints in the government publication. 
The acts have come before the courts for construction, therefore, with apparently little to indicate legislative intent. Where the word accident has been used, as in the British Act, ${ }^{10}$ to which our own system goes back immediately, the employment of the term has often been regarded as an indication that disease was not included in the compensation system. The silence upon this specific point in legislative acts and in discussion aiding in the determination of legislative intent has been construed at times as indicating that the legislature was dealing exclusively with what was regarded as the main feature of the subject, accident. Some of the acts have set the question at rest by a positive provision that diseases other than those which resulted from a definite trauma were excluded. ${ }^{11}$

In two adjoining New England states having in general much the same system of jurisprudence, the question was open so far as any very clear indications of intent were concerned. The courts of the two states reached diametrically opposite results. In Massachusetts the question came before the Supreme Judicial Court in 1914 in Hurle's Case. ${ }^{12}$ The workman there suffered from an acute attack of optic neuritis induced by poisonous coal tar gases. He had worked about furnaces for producing gas by the burning of coal, in the top of which were several holes through which, after opening a cover, he could watch the fire. It was necessary, in the performance of his duty, for him to open the holes many times a day and whenever they were opened poisonous gases issued. The inhalation of these gases caused blindness. The court, through Chief Justice Rugg, considers the case as presenting a situation where particles were thrown in much the same way as pieces of coal might have been thrown and holds that there had been a "personal injury." The court regards the size of the object and the way in which it does its work as immaterial. It emphasizes the fact that the

${ }^{10}$ The British Act of 1906 is easily accessible, not only in its original form, but in the reprint in 2 BRADBURY, WORKMEN's COMPENSATION (2d ed. 1914) 1735 et seq. Occupational diseases came into the British system by an act of Parliament subsequent to the original legislation. The statutes up to 1925 are collected in ELLIOTT, WorKMEN's CoMpensATION ACT (8th ed. 1925).

${ }^{11}$ As in Iowa, where the statute reads, "The words 'injury' or 'personal injury' shall be construed as follows: . . . . They shall not include a disease unless it shall result from the injury."

12217 Mass. 233, 226, 227, 104 N. E. 336, 338-339 (1914). It is thero said, "if the gas had exploded within the furnace and thrown pieces of 'cherry' hot coal through the holes into the workman's eyes, without question he would have been entitled to compensation . . . There appears to be no sound distinction in principle between such case and gas escaping through the holes and striking him in the face whereby through inhalation the vision is destroyed." 
Massachusetts Act, differing from the British Act and those of many states, omits the word accident.

In Johnson's Case, ${ }^{13}$ decided a few months later, the malady was lead poisoning, a definitely occupational disease. The employee had for twenty years been absorbing lead poison. The award of compensation was sustained. Perhaps it may be said, therefore, that according to the Massachusetts theory the disease is really the consequence of a trauma, but that instead of one blow with a definite result the trauma is made up of an almost infinite number of incidents which, each in itself unimportant, are serious when preceded or followed by others. Obviously, this view extends to diseases generally, assuming only that we have the untoward condition growing out of industry, and the causal relation between that condition and the disease. The Massachusetts cases are thus typical of one view to be taken of the problem. The word injury is taken to comprehend not only a single definite trauma producing a marked result, but a series of invasions, insignificant taken individually, but when combined capable of producing incapacity or death.

In Connecticut, the statute as it stood early in $1915^{14}$ bore a strong family resemblance to the MLassachusetts Act. The word accident occurred in but one place, ${ }^{15}$ which was in connection with reports and where its inclusion might well have been explained, as it was explained in the dissenting opinion in the case to which reference is about to be made, as resulting from inadvertence.

The act had much in the way of legislative history to affect its interpretation, however. A commission, for instance, had been appointed, which had made a report, and there were legislative debates, the record of which had been preserved. The act of that state, like that of any other, had of course to be construed as a whole. A case involving ten dollars in money, but a great deal in point of principle, arose in the administration of the act, and compensation was awarded for lead poisoning. In due course of time it reached the Supreme Court of Errors and was made the subject of one of the leading compensation cases of the state, and in fact of the country. ${ }^{10}$ The conclusion of the court was diametrically opposite from that which had been reached in Massachusetts, and it was held that, in order that compensation be granted, there must be something different from a series of exposures each harmless in

\footnotetext{
13217 Mass. 388, 104 N. E. 735 (1914).

14 Conn. Pub. Acts 1913, c. 138, pt. B.

15 Ibid. $\$ 20$.

IE Miller v. American Steel and Wire Co., 90 Conn. 349, 97 Atl. 345 (1916).
} 
itself. There must be a definite event attributable to time and place.

This case furnished the text and the starting point for legislation which has occupied the attention of the General Assembly of Connecticut for nearly every session since then. The necessity for the existence of an incident attributable to time and place was removed by legislative enactment, ${ }^{17}$ and it was said that the word injury should be construed to include a disease, if not communicable, which was due to causes peculiar to the occupation. There was added to the definition clause of the statute a provision that the word injury should include occupational diseases.

The construction of the Connecticut act is an interesting story, but aside from our present object. It has presented a picture of decision construing statute, statute changing the result of decision and decision again construing the statute working the change. In the process the distinctions necessarily became finer and finer. Before the sitting of the General Assembly of 1927 it was believed that the different interests-those of the employers, insurers and employes, as well as the public itselfwould present their differences with results that it would be difficult to prophesy. The matter took such form, however, that there was no contest before the legislature, and legislation was passed which made rather sweeping changes in the subject of compensation for occupational diseases. The effect, and even the construction of that legislation are for the future. While the underlying principles remain, the general tendency of the Connecticut legislation is to narrow the scope of the compensation in such cases.

Disaases in General Made Compensable by Express Language. The instances are rare where by express language the compensation system is extended to cover diseases in the same broad and general way that it covers accident. One of the exceptional illustrations is found in Connecticut in the legislation following the Miller case to which reference has just been made. . The reason for this is obvious. There is such difficulty and uncertainty in tracing causal connection between the hazards of work and disease that the states have hesitated to carry the compensation principle to its logical conclusion.

Compensation for Scheduled Diseases. There are certain diseases which are practically restricted to industry and where the causal connection is not difficult to establish. What may be, therefore, still called the typical form of act for the compensation of occupational diseases confines its operation to a few diseases of this character, stating in general terms that com-

17 Conn. Pub. Acts 1919, c. 142, §§ 1, 18. 
pensation shall be awarded for such diseases as are included in a schedule, in one form or another made a part of the act.13 In this respect the British Act has been often taken as a model. It is in effect a supplement to the original Eritish Act providing compensation, and gives a similar form of relief in case of occupational disease.

In this form of legislation logic is frankly leît behind and, by the adoption of a schedule which must necessarily be artificial, it is sought to secure practical results in the form of compensation in a large percentage of cases where compensation should be granted. There are necessarily many gaps, and many meritorious cases must go without relief. On the other hand, it eliminates much guess-work, and avoids a great deal of danger which would otherwise exist of compelling industry to pay for that for which it is not responsible.

The mention of this form of statute naturally leads to a consideration of the question of what, after all, is an occupational disease.

Disease Resulting from a Definite Trauma. In considering this phase of the subject, we are at the outset met with the question of what is the position of a disease which, instead of coming on gradually as a result of working conditions, has grown out of a definite trauma. One who suffer's a fall may develop pneumonia under such circumstances that the causal connection may be established. Under conditions the result of which may be more debatable we may have a case of frostbite and a resultant erysipelas. A definite accident may cause a nephritis or a pneumonia. The question occurs, therefore, as to whether we are dealing with an occupational disease proper, or simply with a sequela of a definite trauma. Whether by express provision of statute, or whether by construction of law, the conclusion is generally reached that these results do not

18 The schedules sometimes not only set out the specific diseases, but indicate the processes, thus further limiting the scope of the law. Thus in Ohio, the schedule begins-

"Description of disease or injury,

1. Anthrax

2. Glanders
Description of process,

Handling of wool, hair, bristles, hides and skin.

Care of any equine animal suffering from glanders; handling carcass of such animal."

This restriction in that state is, however, of very limited effect, as the remainder of the schedule is illustrated by the next item;

"3. Lead poisoning

Any industrial process involving the use of lead or its preparation or its compounds."

Ohio Gen. Code (Page, 1921) § 1465-68a. 
represent occupational disease, but conditions which are compensable even though the compensation system is confined to accident and does not extend to occupational disease in the abstract. This result, that a disease growing out of a definite trauma is compensable, is generally reached as a matter of construction. In many of the statutes, however, the principle has been expressly incorporated..$^{10}$

Occupational Diseases in Their Nature Like Other Diseascs. Of occupational diseases, it is to be remembered all the time that they do not differ essentially from diseases of a different origin. As said by Dr. W. Gilmore Thompson in the pioneer work on the subject in this country: ${ }^{20}$ "Occupational diseases are not new diseases from the ultimate pathological standpoint." The author illustrates by noting that the arterio-sclerosis or chronic nephritis produced by lead poisoning does not differ from that condition when induced by alcoholism or other toxic causes and he further instances the case of bone necrosis from phosphorous poisoning which is said not to differ from necroses of other origin. Probably no disease exclusively of occupational origin exists. In the vast majority of cases lead poisoning is of occupational origin, but obviously it can be contracted in one's home as well as in a factory provided the conditions are there. Even the more obscure and unusual diseases which arrest the attention in the schedules of the occupational disenses act, such as anthrax, could obviously be contracted outside of industry.

The difference between the diseases which ordinarily present themselves to the mind as occupational, and those which make another impression, is that the former are in a sense characteristic of industry and ordinarily met with as a consequence of industry, while the latter are commonly of non-occupational origin. The distinction is not exact, but is employed for a thoroughly practical purpose in the way of attempting in the great majority of cases to charge against industry only those results which it should bear.

Diseases Compensable Because in Turn Caused, by Compensable Diseases. The disease may be compensable because it is in itself such a disease as is directly covered by the statute, whatever the form of that statute may be. On the other hand, it may owe its compensability to its relation to another disease. Thus there may be a disease which, if it stood by itself, would not be compensable, for which compensation may nevertheless

\footnotetext{
19 For instance, in Maryland, the statute defines injury as inclusive of "such disease or infection as may naturally result therefrom." Md. Codo (Bagby, 1924) Art. 101, § 65.

20 Thompson, Occupational Diseases (1914) 48, 49.
} 
be granted on the ground that it is a sequela of compensable disease. No better illustration of this can be found than that arising under the statute until recently in force in Connecticut which denied compensation for a disease of a communicable nature. It would be universally admitted that tuberculosis is communicable. It would seem that tuberculosis growing out of industry and preceded by no other disease would be, under a statute of the nature to which reference has just been made, noncompensable. If, however, the tuberculosis is simply a result of the disease called pneumoconiosis-a fibrotic condition of the lungs caused by inhaling metallic or mineral particles-compensation may be granted for incapacity or death due to it..2

There are several things which cause complications when the principle of workmen's compensation is extended to occupational disease. Only under rare circumstances does compensation for an accident affect two employers; commonly an occupational disease grows out of more than one employment. In general terms it may be said that an attempt-often a very rough oneis made to charge up against each employer the results in the way of occupational disease of what happens in his own undertaking. These results may manifest themselves either during the time of the employment with a particular employer, or after the service has ceased. That in itself is an immaterial element. Sometimes this division of responsibility results from the use of mere general language but in some of the statutes there are express provisions determining the respective liabilities.

It has generally been deemed impracticable by the legislators to cover a period longer than a few years, although theoretically results should be recognized as long as they can be traced back to causes. The obvious difficulty is as time goes on to determine what are the results of industrial causes and what are the results of that which has no legitimate connection with the industry. To weigh accurately the responsibility of each employer is beyond human power. The statute law often contents itself with a proportion based upon the periods of service; often, on the other hand,-and this is most apt to be the case when the statute is couched in general telms-other elements are taken into account, such as the hours of labor, the varying degrees of exposures and the different hazards incident to the exposures. Where this is done the division is less frankly

21 Kovaliski จ. Collins Co., 102 Conn. 6, 11, 128 Atl. 288, 290 (1925), where it is said: "But in this case, the injury which developed with grinder's consumption was a weakened resistance to infection called pneumoconiosis. This was an injury not contagious or communicable." That pneumoconiosis is itself a disease seems to be assumed. Dombrowsli v. Jennings \& Griffin Co., 103 Conn. 720, 727, 131 Atl. 745, 748 (1925). 
arbitrary, but much more subject to the uncertainties incident to the exercise of human judgment.

The results of accident do not generally become intermingled and confused with the results of causes with which the employer has no concern; intermingling and confusion are common complications in an attempt to award compensation for occupational disease. As said by Professor Thompson in the work already cited: ${ }^{22}$

"It may be claimed that the workman is the victim of chronic lead poisoning; but are his arterio-sclerosis and nephritis due exclusively to lead poisoning, or are alcohol, syphilis or gout the underlying causes? Is his neuritis due to arsenic or alcohol? $* * * *$ Was he turberculous before he undertook work in $\approx$ pottery, or did his work contribute to the disease? Are his chronic bronchitis, anemia and malnutrition due to chronic gas poisoning acquired as a garment presser, or are they due to defective hygiene at home, poor food, lack of exercise, and the strain and anxieties of poverty? Such are the types of questions which constantly arise in connection with occupational diseases."

Obviously, however, we are dealing only with questions of degree. The same intermingling, with the same resulting confusion and uncertainty, may exist in accident as in disease. The difference is that in the one case it is comparatively uncommon and in the other so common that it may be said to be almost generally. present.

It is easy in the vast majority of cases to distinguish between an accident in industry and one which has arisen out of ordinary living; in occupational diseases the difficulty of making this distinction is at the maximum. Naturally, the broader the scope of the compensation for occupational diseases the greater is the difficulty of determining what in a particular instance is an occupational disease and what is not. One would hardly get pneumoconiosis at home and would probably run but a small chance of coming down with lead poisoning. If, on the other hand, tuberculosis is included among occupational diseases the difficulty of making the distinction becomes acute. In all of these questions appearances are apt to be deceptive. It is the view of many physicians who have given attention to this subject, for instance, that one of the safest employments so far as tuberculosis is concerned is that of an attendant in a sanatorium for the tubercular.

Speaking broadly, the compensation acts are inclined to disregard the particular kind of employment and the particular kind of accident. It is to be remembered here, however, that in many jurisdictions a distinction is made between hazardous and

${ }^{22}$ Thompson, op. cit. supra note 20 , at xxiv. 
non-hazardous employments in granting compensation for results of accident. This same distinction often inheres in statutes covering occupational diseases, and the different industries are sometimes classified by schedules, the compensation for certain diseases being restricted to certain lines of work.

Where there are different employments and the employee is sick as a result partly of one and partly of the other, there are two methods observed by statutes, as those statutes are construed, of approaching the problem as to the liability of each. The disease may be treated as an entity in the first instance and the effort then made to weigh responsibilities for it. It may on the other hand be viewed as a disease caused by the first employment and aggravated by subsequent employments, the first employer being responsible for what the results would have been had the employee stopped work, and the subsequent employers being responsible for aggravations.

There is no reason in the nature of things why an employer whose work aggravates that which a previous employment has begun should be in any different situation than one whose work aggravates that which has been begun outside of employment. Where, however, the principle of compensation for aggravation has come in as a part of an occupational disease system, the view has been taken that the responsibility of the employer is limited to aggravation only where the disease originated in employment, and that where the disease originated out of employment the unfortunate employer must foot the whole bill.23

In accident, medical testimony, while it plays a very large part, may be important only in determining the amount of compensation; the very right to get compensation for occupational disease at all will probably rest upon what the doctors say. The way in which the medical man functions in the administration of compensation acts varies greatly. In some states no physician has an official standing. He is like any other witness called by one side or the other, and the weight given to his testimony is determined by the same considerations as the weight which would be given to him as a witness in a law suit at common law. In other states, there is contemplated the appointment of a physician or physicians who are definitely public officers. Often their findings determine in the first instance the medical aspects of the case. If disputed, however, other medical testimony is heard. In a general way, there is a legislative tendency in the determination of compensation for occupational diseases to create a more definite medical machinery than in the case of compensation for accident. The same gen-

${ }^{23}$ Bongialatte v. Wales-Lines Co., 97 Conn. 548, 117 Atl. 696 (1922). 
eralizations, however, may be made in the one case as in the other.

\section{SOME THOUGHTS ON AN IDEAL OCCUPATIONAL DISEASE} COMPENSATION ACT

The experience of the states in the last decade suggests certain characteristics of a proper occupational diseases act.

First: It should be simple in its framework and should be coordinated with the parent legislation. If changes are made in one, corresponding changes should be made in the other when necessary to the existence of a consistent whole. The administration should be confided to the same officers or to the same board.

In other words there should be in effect one system growing out of the same social need, involving intrinsically the same problems and calling for the same relief. Special provisions may be necessary in the effort to compensate for the one kind of industrial waste, which are not needed in the same form in attempting to compensate for the other. On analysis, and further experience, however, the necessity for varying provisions tends to fade away. In some jurisdictions now the two problems are worked out as one.

Second: We can not forget the wealnesses of human nature and the proneness of human beings to attempt to escape effort. We can not lose sight of the fact that justice must hold even scales between those who pay and those who are to receive. We must seek to avoid temporary injustices during the period of adjustment. We must do everything possible to protct the employer from real malingering and a sort unintentional quasimalingering.

Third: Preserving all these cautions, the real object must be kept steadfastly in mind and a serious attempt made to place the workman in the same position, so far as the case admits, as though he had remained well and sound. This involves the allowance by way of compensation of as large a percentage of the wage as is possible and its payment, in so far as may be, for the full period of incapacity, with a compensation period in case of death sufficient to make good to his dependents the financial loss which they have sustained. No system of law ever afforded full redress. There must always be a yielding to practical exigency. Money can never make good the most serious losses. The necessity for some sort of demonstration or something approaching demonstration may cause recovery to fall far short of full relief. To this general limitation a compensation law can afford no exceptions. As a counsel of perfection per- 
haps it should be borne in mind that the relief should be as adequate as it can be.

Fourth: The provisions as to medical aid should be fair and liberal. The earlier workmen's compensation legislation generally allowed medical assistance which could hardly be dignified with a higher name than "first aid." The movement has been all in favor of an extension of this period. In Connecticut full medical aid is now allowed and this is construed to mean such medical assistance as the circumstances call for, whatever its expense and wherever it is obtainable. This gives a broad commission to the administrator and it is of course assumed that the law will be administered with common sense.

Such liberality is obviously in the interest not only of the employee but of the employer as well, in that it tends to decrease the compensation and is in the interest likewise of the general public. Under the Workmen's Compensation Act there is now expended in Connecticut substantially the same amount for medical aid as for compensation itself. Wherever practicable, the worker should be restored to the ranks of industry rather than given a place upon a pension list.

One of the surprising and gratifying incidents in the administration of workmen's compensation of all hinds has been that the cure of the injured and diseased has enlisted the aid of medical men of high standing. The cheap and incompetent doctor has by no means been eliminated, but he has not been much in evidence. The employers, who have in one way or another paid the bills, have early found that the best is the cheapest and have turned, in the vast majority of cases, to physicians of standing, whether actuated by the highest motives or merely by economy. Where the oversight of medical treatment is, as it generally is in one form or another, in the control of those administering the act, it has proven that the authority thus confided is seldom to be exercised. The importance of the physician in this connection will always be great. Where it is deemed necessary to so commission a certain physician or body of physicians that their findings constitute prima facic the medical facts, there should be the fullest opportunity to weigh those findings, with every right of cross-examination preserved and every opportunity to present differing views through expert witnesses.

Fifth: The law should be so framed as to do justice to the employer by protecting him from illnesses which his operations have neither caused nor aggravated. He should receive this protection whether the other: inducing causes arose out of another employment, or from non-occupational causes. He should be guarded against the natural tendency of mankind to either intentionally or unintentionally get something for nothing. 
The workman should likewise be protected against himself by properly encouraging him to make reasonable efforts to the end that he may retain his ambition and self respect, and that the psychic effects of what has happened to him may be minimized. Here the interests of the workman, the employer and society are one. In this way each industry will pay its part.

Sixth: The law should go so far as it can to measure the responsibility of each employment without landing in a maze of guess-work, complication and uncertainty. In fixing the period of compensation the law should look ahead, so far as is practicable, but stop short of the twilight zone where, owing to the existence of other elements, it is impossible to trace cause and effect.

\section{LOOKING AHEAD}

After all, while compensation for accident is now made in the majority of the American states, the compensation of occupational diseases is in its infancy, and clean-cut provisions of any general applicability exist as yet in only about a third of the states. In others the system is fragmentary and does not yield itself readily to statistical efforts. What has been done in the past is interesting mainly, as an index of what may be expected in the future. If the principle of compensation be sound, and no doubt is now entertained on that head, it must be that the development of this branch of the system is sound also. To an increasing extent industry will stand behind the results of occupation when those results are expressed in terms of disease.

Differences, although tending gradually to disappear, will remain in the scope of the relief afforded, in the procedure and in a hundred details. It may be confidently asserted, however, that the law will move forward and not backward.

Upon the points suggested as the characteristics of an ideal law there will be found, so long as they are stated abstractly, something approaching a unanimity of opinion. They are in a way being worked out with much variation in detail in the acts now upon the statute book, with a development in the direction of unformity. Legislation along any line is apt to be a compromise, and this is particularly true of that involving the relations of different elements in our society.

The whole conception of compensation for disease independently of fault is comparatively new. The legislation is often crude. The construction represents the attempt of courts to deal with new legal conceptions. We are far from having heard the last word. We are surely on the way, however, toward real justice and high social ideals. 